\title{
Climatic Considerations and Their Role in Explaining Sustainable Development of Urban Environments
}

\author{
Aryan Amirkhani and Fatemeh Tehrani
}

\begin{abstract}
The issue of sustainable urban development has been considered an important scientific issue in all communities in recent years and has received a large part of the literature on urban development. In this regard, various dimensions of sustainable development from different angles have been studied, analyzed, and evaluated, and various approaches have been considered in different perspectives. By defining sustainable development as development of quality of life and life in the capacity to tolerate backup ecosystems, and with regard to concepts such as development and the environment, the relationship between human, the environment and sustainable development is explained in the context of this definition.

Various causes play a role in the formation and sustainable development of urban environments, among which climatic considerations play an important role. Climate as one of the subsystems involved in the ecological structure of nature with other components of the system has interacted with each other and thus reacts to the changes occurring in the natural systems and adapts itself to new conditions.

Within the framework of this discussion, the following climatic changes are briefly discussed. In fact, these are the changes that, in the sense of "urban climate", give a special identity:

1. Irradiance, transparency and / or air turbidity; 2. Air temperature; 3. Air flow or wind system; 4. Humidity; 5. Quantity and quality of atmospheric precipitation; 6. Air pollution

After mentioning the factors affecting the urban climate, climatic solutions and considerations in urban spaces can be briefly analyzed in terms of performance in places such as walking paths, riding paths, and green spaces.
\end{abstract}

Index Terms-Climate, urban environment, sustainable development, urban components, environmental factors.

\section{INTRODUCTION}

The environment refers to a set of physical elements, social and economic conditions, and generally refers to phenomena and events that involve man or are organized by him. Today, the role and importance of the environment in the formation and occurrence of human behaviours do not need to be demonstrated. To better utilize capital and resources, all aspects and dimensions of environmental design should be considered, including users' needs and conditions. Designing, planning, and adapting the environment should look for its role and responsibilities in deeper and wider areas than human beings, life and complex relationships within it. In the relations between humans and the surrounding environment,

Manuscript received May 24, 2019; revised August 14, 2019.

Aryan Amirkhani is with Tarbiat Modares University, Tehran, Iran (e-mail: aryan.amirkhani@gmail.com)

Fatemeh Tehrani is with Geography and Urban Planning, Islamic Azad University, Science and Research Branch, Tehran, Iran. sustainable development has always been a fundamental concept [1]. By defining sustainable development as development of quality of life and life in the capacity to tolerate backup ecosystems, and with regard to concepts such as development and the environment, the relationship between human, environment and sustainable development is explained in the context of this definition. Various causes play a role in the formation and sustainable development of urban environments, among which climatic considerations play an important role. Climate change in urban environments, including natural reactions to current interactions in urban environments, can be considered in two dimensions:

1) Climate as one of the components of ecological systems.

2) Climate as a natural and open system

Climate as one of the subsystems involved in the ecological production of nature with other components of the system is in mutual interaction, and therefore responds to changes occurring in natural systems, and adapts itself to new conditions.

Therefore, any change in the system of nature in some ways leads to the occurrence of climatic changes. In the next step, the climatic factor can be considered an independent natural system (relative independent meaning). The climate system is also an open and dynamic system, and for this reason, every change is made in other components of the climate system. Whenever enough attention is paid to the last two points, the complexity of the explanation of climatic variation is self-evident. At the same time, it should be noted that within the framework of urban studies, as a result of this study, only climate change is considered, which occurs at the maximum on the microclimate scale. Nevertheless, we also know that macroclimate, under the influence of ozone layer erosion and increasing the thickness of the greenhouse layer of Earth envelope, is a profound climatic development that undoubtedly affects the microclimates; as a result, the urban climate will be affected by its consequences. Within the framework of this discussion, the following climatic changes are briefly discussed. In fact, these are the changes that, in the sense of "urban climate", offer a special identity: 1). Irradiance, transparency and / or air turbidity; 2). Air temperature; 3). Air flow or wind system; 4). Humidity; 5). Quantity and quality of atmospheric precipitation; 6). Air pollution [2].

After mentioning the factors affecting the urban climate, climatic solutions and considerations in urban spaces can be briefly analyzed in terms of performance in places such as walking paths, riding paths, and green spaces. Obviously, these considerations are factors influencing urban environments. At the end, the results of the above discussion are expressed. 


\section{DiFFERENT CONCEPTS AND DiMENSIONS OF SUSTAINABLE URBAN DEVELOPMENT}

Ambiguity in the sense of sustainability has led to a kind of uncertainty in the concept of sustainable urban development. There are many researches to overcome these doubts, but they are not still sufficient. The city is a complex system, and as the larger it is, the result of development measures will be more unpredictable. However, the two concepts "urban sustainability" and "sustainable urban development", which are often used owing to their proximity to each other, should not be mistaken with each other. To distinguish these two, we must note that sustainable urban development, in fact, represents the process during which stability can occur, but stability is a set of situations that persists over time. However, some consider sustainable development in utilizing land and encouraging the reuse of buildings, and maintain that the size, density and location of human habitats suitable for sustainability, will be variable in line with the development of technology in energy, production, building, and transportation. Some also define sustainable development as a way of improving the quality of life and life in the capacity of bearing backup ecosystems. In each form, various factors and dimensions are effective in sustainable urban development; climate and environmental considerations are only one of them [3]. Table I summarizes the importance of sustainable urban development.

TABLE I: IMPORTANT DIMENSIONS FOR SUSTAINABLE URBAN DEVELOPMENT

\begin{tabular}{|c|c|}
\hline & OEVELOPMENT \\
\hline \multirow{5}{*}{$\begin{array}{c}\text { General considerations in } \\
\text { planning for sustainable } \\
\text { urban development }\end{array}$} & 1. Economic considerations \\
\hline & 2. Social and cultural considerations \\
\hline & 3. Physical considerations and principles \\
\hline & $\begin{array}{l}\text { 4. Management, decision-making and } \\
\text { executive practices }\end{array}$ \\
\hline & $\begin{array}{l}\text { 5. Climatic and environmental } \\
\text { considerations }\end{array}$ \\
\hline
\end{tabular}

\section{Climatic And Environmental Considerations}

In the following, some of the main factors affecting climate change are mentioned, which are important in the study of urban environments and planning for sustainable urban development.

\section{RADIATION AND AIR TURBIDITY}

A commonplace reality, which has disappeared from the realm of consciousness of man is that the energy needed to maintain and sustain life on the planet is received from the sun. However, if the planet was to receive only solar energy, it would have to increase its temperature regularly. Nevertheless, since such a situation does not occur in natural conditions, it must be admitted that the earth also reflects energy to the atmosphere. It is precisely for this reason that the energy received and the reflected energy must be assumed to be a kind of equilibrium. Research in recent years has indicated that the balance between two energy streams is disrupted, which is why the temperature of the earth is increasing. In natural conditions, to establish balance between the received energy and reflected energy, there are a number of very complex and sensitive processes between the sun, the space above the atmosphere, the atmosphere and the earth. The emergence of climate change on a global scale is an indication of the disruption of the natural process of these processes. In urban environments, air pollution causes changes in the way solar radiation enters the earth's surface. As air pollution increases, the amount of solar radiation received by the earth is reduced, and the amount of reflection by the polluted layer over the city is increased. In this regard, the amount of suspended matter and aerosols in the city has a decisive role. When there is polluted air over the city, it prevents ultra violet short wave transmission (less than 0.36 micron) and reduces its input. The visible light spectrum along the ultraviolet spectrum is weakened by passing the polluted atmosphere. Under the influence of suspended particles in the air, direct light is dispersed and the ratio of these two to each other differs in favor of diffuse light. Reduction of the clarity of the lines and edges as well as decrease of the range of vision are among the most significant consequences of these changes. In the distribution of sunlight, the horizontal and vertical arrangement of the city also interferes. In the streets surrounded by high-rise buildings, the roofs of the buildings become the main source of energy exchange. The sidewalks and the lower parts of the buildings mainly receive reflections from the roofs and walls.

\section{Changes In URBAN AIR TeMPERATURE}

The emergence of changes in air temperature in urban environments should be considered in several ways: increasing thermal energy discharge in the air, changes emerging in thermal energy distribution, increasing the city's capacity for thermal storage. A massive amount of thermal energy is daily discharged from the combustion of fossil fuels (home supplies, motor vehicles, industrial resources), and this amount of energy is steadily increasing along with population growth and industrial activities. Changes in the natural system will result in climate change. Air pollution reduces the clarity of the lines and the vision range. The use of old and outdated techniques for the use of fossil fuels not only increases the pollution of the air, but also exacerbates its consequences. In a situation where the condition of the city's airspace - whether for natural reasons or because of the inappropriate design of the city's macroform - is disturbed, this thermal energy, which is abnormally discharged into the environment, can have profound changes in the climatic structure of the city. In urban environments, thermal distribution also changes strongly due to the change in the level of thermal exchange resulting from urban constructions [4]. Regarding the different levels that a building can have, the levels of its thermal energy received, in comparison to the land surface occupied by the building, are multiplied by several times, and the same amount of received and reflected thermal energy is multiplied. In other words, increased levels of construction and the multiplicity of buildings in the city have a direct impact on the production and consumption of solar energy in the city. In addition to increasing the storage capacity of thermal energy, a kind of movement in the process of increasing and decreasing the temperature of the city also occurs. In the warm months, the heat storage in the building's structure makes it possible to 
delay the cooling of the city during the night, since at this time, the walls, ceilings, paving blocks discharge the thermal asphalt levels stored during the day, thereby delaying the natural cooling process of the environment. The phenomenon is directly related to the size of the city and the multiplicity of buildings. The city's thermal capacity especially increases when the city is poor in terms of heat-absorbing spaces and surfaces (urban forests, extensive trees, lakes and wetlands).

\section{Changes In AIR Flow AND Wind SySTEM}

The wind system can be classified into two major groups:

Regional winds that have developed in the macroclimate range and in different months and seasons, are influenced by a pattern that is more or less specific to a particular space.

Local winds that appear in Dashtkouh and Kouhdasht flows in most of the mountain cities of Iran. In the coastal areas of the north and south of the country, they are also among the typical local winds.

Certainly, in many other parts of Iran, there are other local winds that mentioning them one by one is outside the current discussion framework. The important point here is that the macroform, as well as the arrangement of the spatial organization of the city, can have a serious impact on the natural process of winds and, consequently, the role that winds can play in ventilating and purifying the city's air. Here, the role of the city's size, the multiplicity of buildings, and the design and organization of the height of the city's buildings are well revealed. Increasing friction within the city limits, makes the movement of the air difficult, especially to a height of 1000 meters from the surface of the earth. Part of wind energy is used to counteract frictional forces when passing through and over long, short-lived structures, and therefore its speed is reduced. Furthermore, when the air flows into the city, a "pillow from the air" is created on the city, which is followed by the flow of air. The air flow that moves on this pillow cannot penetrate the surface of the earth and help to ventilate the city's air. The situation intensifies when the air corridors to the city are blocked by high-rise buildings [5]. In the streets, the wind conditions vary, depending on how the spatial arrangement around the street borders, the green spaces, and the wide, long or short buildings, changes. The street that are built in the direction of the prevailing winds and are surrounded by long and narrow buildings usually increase wind speeds. The joint effect of urban construction, thermal island, and wind flow is also significant in urban environments. Thermal islands are usually formed in the densely populated areas of the city with poor thermal discharge. In this dense atmosphere, the air close to the ground surface is warm and light, and climbs upwards. In this case, a low pressure center is formed which can cause air pollution around the city. Such a phenomenon can have both positive and negative aspects. In a case where the city is surrounded by extensive forest parks and water levels, the air that is blown into the city is a clean, oxygen-rich air and, therefore, can help to ventilate and increase the city's air quality [6]. Moreover, when the city has been occupied by industrial and polluting air around the city, the air entering the city is mainly polluted air, which can ultimately affect the air pollution of the city. The above-mentioned situation can be considered absolutely true in the case of Tehran, and relatively true in the case of Isfahan. In the case of Tehran, from west to southwest and no local winds of Dashtkouh, none of them can considerably contribute to the air conditioning of the city. At the same time, it should be noted that, in terms of air purification, only when the wind speed reaches more than $3 \mathrm{~m} / \mathrm{s}$, it can play an effective role. However, in Tehran, due to its unorganized macroform, as well as the natural weakness of the winds, the air conditioning capacity of the city by this climatic factor is very low.

\section{CHANGES IN AIR HuMIDITY}

Identification of air humidity in urban environments, like air temperature, has its own complexity. This complexity in the cities of Iran, which is in the Iranian Turanian plant territory from the perspective of plant geography (the vast majority of Iran, with the exception of the north biome of the Alborz mountain ranges and the biome under the influence of the Persian Gulf and the Oman Sea), becomes more complicated for several reasons:

This plant area, in its natural range in its plains, is formed of mostly tight trees land, bush, shrubland, semi-desert and desert steppes. The characteristics of these areas are long-term drought, and therefore numerous bioclimatic constraints and very limited ecological vulnerability. When a place from this plant kingdom turns into a city, the ecological construction of the natural environment generally changes. The outcome of these changes, which will be discussed below, brings the urban climate to the point of drought more and more.

On the other hand, the creation of urban green spaces with irrigation, the creation of agricultural lands around or near the city, the creation of artificial forests to deal with the sand, the massive use of fossil fuels in the city increase air humidity. Thus, as seen, in urban environments, there are two completely opposite flows that move the environment toward the drought and the other to increase the humidity of the air [7]. In the past, some changes have been made, which will increase the temperature of the city. In such a situation, it is obvious that the city's air is becoming dry. Nevertheless, this hypothesis does not always turn into reality. The existence of private, semi-private and public green spaces, which in Iran's dry environments always require irrigation, some moisture enters into the air by evaporation of plants, and as a result of water evaporation from the surface of the soil. It has also been mentioned that fossil fuels after combustion always enter some water vapor into the air. For example, as a result of combustion of one liter of gasoline in a vehicle, one cubic meter of vapor is produced into the air. The city of Tehran is a prominent example of this situation; in this city, it was expected that by 8 million liters of gasoline daily, 8 million cubic meters vapor would enter into the air. In addition, gas produced from gas, gasoline, oil and mazut should also be considered. At the same time, as the traditional architectural style has changed into a so-called modern architecture, the use of cooler has become essential in many buildings. On the roofs, air conditioners are exposed to intense sunlight on the 
one hand, and on the other hand, due to technical defects, in most cases, there is a significant loss of water. These two factors, each with their own share, can enter some moisture into the air.

\section{THE APPEARANCE OF CHANGES IN ATMOSPHERIC PRECIPITATION}

Climate in the concept of the weather pattern in a given time and place is the product of the joint operation of various meteorological factors and therefore follows the rules governing the open and dynamics systems. Therefore, as previously mentioned, if one or more parts of the system are changed, the other components will change in order to adapt to the new state of the system itself. Therefore, due to the climate change mentioned earlier, it can be expected that the trend of rainfall in urban environments will also change. This climate change also applies to climate as a subsystem of the natural system and the climate as an independent natural phenomenon [8]. The most obvious form of these changes is the reduction of precipitation in the form of snow; this phenomenon, as a manifestation that has occurred over the last few decades, has even played a role in the memory of most citizens. Most scholarly sources emphasize the fact that under conditions of decreasing precipitation, snow is added to the amount of rainfall. However, due to lack of sufficient information on the climatic condition of Iranian cities, this claim cannot be commented on the validity of this claim. In addition, the frequency of lightning and heavy rainfall are also attributed to urban climate. Furthermore, the frequency of the occurrence of convective rains or rains arising from the rapid movement of hot air based on the city is also considered the characteristic of urban climate. When the hot air, mounted on a city in a state of high instability, climbs upwards, this displacement and rapid drop in temperature can lead to convective rainfalls. A typical example of this phenomenon was the black rain after the fire of the mazut pools of Tehran Refinery in April 24, 1986. In those conditions, the massive amount of heat energy discharged in the air climbed upwards and quickly climbed into the upper layers of the air, causing rainfall. At the same time, since the amount of soot was discharged through the burning mazut, the soot was washed by rain and returned to the earth as black rain. In the winter, in urban environments, plenty of weathering and air pollution are also higher than in open and non-built spaces around the city. In this regard, two main reasons can be mentioned:

Water vapor, which is discharged into the cold air in different ways

Particles of air pollutants acting as primary condensation nuclei and providing conditions for the accumulation of water vapor around them.

\section{Climate Change Caused by Air Pollution}

The above-mentioned climatic changes are directly or indirectly to air pollution. Reduced transparency or increased air turbidity is in direct contact with or increased air turbidity is in direct contact with air pollution by suspended particles, vapors, and chemical compositions of various pollutants in the air (mist smoke of London or Los Angeles). Part of the increase in the temperature of the city should also be taken into account for the city's air pollution. Air pollution also affects changes in humidity and atmospheric precipitation.

The effect of environmental factors on pedestrians as one of the main users of urban space is studied. Then, how sustainable design in urban spaces is functional in terms of designing sidewalks, riding paths, green spaces, and urban furniture [9].

\section{IMPACT OF ENVIRONMENTAL FACTORS ON PEDESTRIANS}

Environmental factors have a significant effect on the residents of the neighborhoods and their willingness to participate in open-air residential areas. The climate is a limiting factor for using open space in very hot or very cold days of the year. Fresh air, suitable temperatures, favorable relative humidity, relatively gentle air flow and protection against rain provide comfortable conditions for humans. All climatic factors such as air temperature, air humidity, solar radiation, wind, rain, and freezing affect pedestrians. By referring to the standard (Penwarden) (Graph 1), it turns out that the temperature range of $16^{\circ} \mathrm{C}$ to $21^{\circ} \mathrm{C}$ is very comfortable for pedestrians.

All climatic factors such as air temperature, air humidity, solar radiation, wind, rain, and freezing affect pedestrians. By referring to the standard (Fig. 1), it turns out that the temperature range of $16^{\circ} \mathrm{C}$ to $21^{\circ} \mathrm{C}$ is very comfortable for pedestrians. At temperatures of $4.4^{\circ} \mathrm{C}$ to $12^{\circ} \mathrm{C}$, the existence of sunshine in thoroughfares is possible, and at $-25^{\circ} \mathrm{C}$, the air is windy and can cause the air to cool on the sidewalk.

Climate and topography are among other factors affecting pedestrians. Water can have heat and cold effects. The greater the amount of water, the more impact it will have on microclimate. Green space also has a considerable influence on microclimate. The temperature of parks is higher at night and lower during the day than the outside space [10]. One of the other climatic factors is wind that can be controlled with vegetation or structural cover.
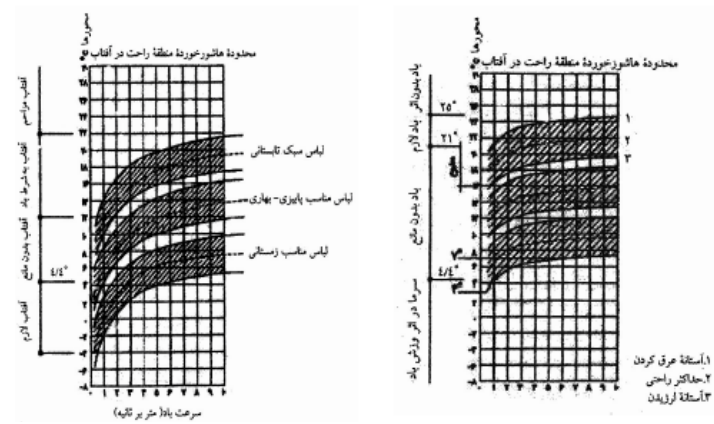

Fig. 1. Comfortable thermal status in terms of wind speed and type of cover for pedestrians according to the standard of Penwarden.

\section{COMPONENTS AND ELEMENTS IN URBAN AREAS}

Sidewalks: The factors to be considered in the design of pedestrian routes are as follows:

Connection of pedestrian routes will be achieved by suitably designing and separating pedestrian path from crossings, nonuse of motor vehicles and bicycles by 
pedestrians, non-occupancy of part of the sidewalk by urban or construction equipment, proper footing of the sidewalk, and not cutting the paths by bridges or natural obstacles.

Short access paths, because passersby usually chooses the shortest route.

\section{Safety of sidewalk routes}

The comfort of the footpaths, some of which are: proper slope, smoothness and stability, lack of slippery footing, adequate width of the sidewalk with regard to pedestrian traffic, comfortable passage of physical and motor skills, and gathering surface water of sidewalk.Green space: Green space is part of the urban open space, where its natural or artificial arenas are under the deployment of trees, shrubs, flowers, grasses and other plants. It is also maintained or created to improve the living, habitat and welfare of the citizens based on human monitoring and management by considering its related rules and specialties. The most important environmental effects of green space in cities are their environmental functions, which include reducing air pollution, reducing noise pollution, producing oxygen and carbon dioxide, controlling radiation and reflecting light, controlling wind, aesthetics, creating shadows and landscapes, and air refinement. The green space, when placed in the urban body, finds the tendency of the urban hierarchy and is divided into different scales in the city. Usually, how to use the green space is determined by the distance indicator and its location in accordance with the urban hierarchy [11].

Urban furniture: Open space consists of various details and components made by mankind, such as sitting places, signs and guides, furniture, and lights.

Sitting places: Sitting is influenced by two specific conditions: climate and space. In short, sitting should only occur where the external environment conditions are desirable and suitable for sitting places that are more accurately selected than standup sites. The considerations that should be taken into consideration when designing sitting areas in open spaces are: Bench type, location of bench placement with regard to the sighted views, types of sitting places and special resting benches for the elderly and people with physical-motor weaknesses [12]. Undoubtedly, observance of the above principles and efforts to control the climate change affecting urban environments are all factors that lead us to sustainable development and sustainable cities.

\section{CONCLUSION}

The issue of sustainable urban development has been considered an important scientific issue in all communities in recent years and has received a large part of the literature on urban development. In this regard, different dimensions of sustainable development from different angles have been investigated and evaluated, and various approaches have been considered in different perspectives. A comprehensive approach to urban development policies and plans, as well as formulation of integrated economic, social and environmental objectives, are at the forefront of policymaking and sustainable urban development planning. Establishment of a balance between large and small urban centers, cooperation between private and public sectors, as well as development of a local strategy are among sustainable urban development policies to be considered. Among various aspects affecting sustainable urban development, climatic factors are important as an influential element. Observing the practical solutions and considerations and attempting to create a balance in the urban environment, in accordance with the climate change, are of the issues that lead us to achieve sustainable development.

\section{CONFLICT OF INTEREST}

"The authors declare no conflict of interest".

\section{AUTHOR CONTRIBUTIONS}

Dr. Aryan Amirkhnai conducted the research and wrote the paper; Urban Issues were mostly considered by Dr. Fatemeh Tehrani; both authors have approved the final version.

\section{REFERENCES}

[1] B. S. Hossein and M. A. Torshizi, "Study of biodiversity basis in urban structure," Journal of Environmental Studies, vol. 23, Summer 1999 Faculty of Environment, University of Tehran.

[2] R. Michael, Sustainable Development, Translation by Hossein Nayyer, Ministry of Agriculture Publications, 1994

[3] B. S. Hossein, "Analysis of urban spaces in relation to behaviora patterns of users and design criteria," University of Tehran, Tehran, 1996.

[4] M. Jean, A. I. Mary, and M. L. Sairy, "Urban spaces, design, implementation, management," Translation by Hassan Rezaie, Public Relations and International Affairs Office of Tehran City, Tehran, 1994.

[5] R. Mahmoud, Comfort by Climate Architecture, Shahid Beheshti University Press, Tehran, 1990.

[6] Ministry of Housing and Urban Planning, Tehran Comprehensive Organization Plan, vol. 10, ATEC Consulting Engineers, Tehran, 1988.

[7] Ministry of Housing and Urban Development, Urban Planning Regulations (Access Pathways), Department of Urban Planning and Architecture, Tehran, 1996.

[8] E. David, Toward an Eco-city, Calming the Traffic, Envirobook, Sydney, 1992.

[9] H. Girardet, "Creating sustainable cities," Green Books, Dartington, 1999.

[10] R. Thayer, Gray World, Green Heart, Technology, Nature and Sustainable Landscape, John Willy and Sons, Inc, New York, 1994.

[11] V. Ryyn, Ecological Design, Island press, Washington DC. 1996.

[12] V. W. McLaren, "Urban sustainability reporting," JAPA, vol. 62, Spring, 1996,

Copyright $@ 2019$ by the authors. This is an open access article distributed under the Creative Commons Attribution License which permits unrestricted use, distribution, and reproduction in any medium, provided the original work is properly cited (CC BY 4.0).

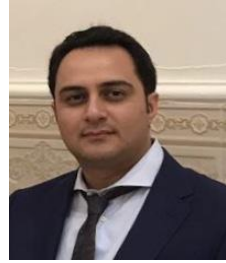

Aryan Amirkhnai is Ph.D in architecture with over 130 national and international papers and 8 books in the field of: (architecture, sustainable design, building's occupants, built environment, vernacular architecture, landscape), Iranian National elite 2010-2011.

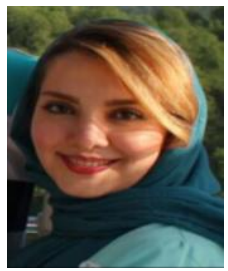

Fatemeh Tehrani is Ph.D in urban design with ove 50 national and international papers in the field of: (urban design, geography, climatic design, building's occupants, built environment and landscape). 